\title{
Correction to: The Development and Validation of a Measure of Science Capital, Habitus, and Future Science Interests
}

\author{
M. Gail Jones ${ }^{1}(\mathbb{D}) \cdot$ Megan Ennes $^{1} \cdot$ Drew Weedfall $^{1} \cdot$ Katherine Chesnutt $^{1}$. \\ Emily Cayton ${ }^{2}$
}

Published online: 21 October 2021

(c) Springer Nature B.V. 2021

\section{Correction to: Research in Science Education https://doi.org/10.1007/s11165-020-09916-y}

Due to an oversight by the Publisher during the typesetting stage, "Author" citations were still present in the originally published paper. The paper has now been updated with the correct citations in the text and inclusion of the missing complete bibliographic entries. Below are the changes:

\section{- Author A, 2006 changed to Tretter et al. 2006}

Tretter, T. R., Jones, M. G., Andre, T., Negishi, A., \& Minogue, J. (2006). Conceptual boundaries and distances: Students' and adults' concepts of the scale of scientific phenomena. Journal of Research in Science Teaching, 83, 282-319.

- Author A, 2018 changed to Jones et al. 2019

Jones, M. G., Lee, T., Chesnutt, K., Carrier, S., Ennes, M., Cayton, E., Madden, L., \& Huff, P. (2019). Enclothed cognition: Putting lab coats to the test. International Journal of Science Education, 42(14), 1962-1976.

- Author B, 2018 changed to Chesnutt 2018

Chesnutt, K., Jones, M. G., Hite, R., Cayton, E., Ennes, M., Corin, E. (2018). Next generation crosscutting themes: Factors that contribute to students' understandings of size and scale. Journal of Research in Science Teaching, 55(6), 876-900.

The Publisher apologizes for this error.

Publisher's Note Springer Nature remains neutral with regard to jurisdictional claims in published maps and institutional affiliations.

The original article can be found online at https://doi.org/10.1007/s11165-020-09916-y.

M. Gail Jones

Gail_Jones@ncsu.edu

1 NC State University, Raleigh, NC, USA

2 Campbell University, Buies Creek, NC, USA 